\title{
A novel program for ABSN students to generate interest in geriatrics and geriatric nursing research
}

\author{
Jennifer Mewshaw ${ }^{1}$, Donald E. Bailey Jr. ${ }^{1}$, Kristie A. Porter ${ }^{2}$, Amber L. Anderson ${ }^{1}$, Ruth A. Anderson ${ }^{3}$, Andrew L. \\ Burd $^{1}$, Cathleen Colón-Emeric ${ }^{4,5}$, Kirsten N. Corazzini $* 1,4$ \\ ${ }^{1}$ School of Nursing, Duke University, Durham, United States \\ ${ }^{2}$ RTI International, Research Triangle Park, United States \\ ${ }^{3}$ School of Nursing, University of North Carolina at Chapel Hill, Chapel Hill, United States \\ ${ }^{4}$ Geriatrics Research Education and Clinical Center, Durham VA Medical Center, Durham, United States \\ ${ }^{5}$ Center for the Study of Aging and Human Development, Department of Biometry and Bioinformatics, Duke University Medical \\ Center, Durham, United States
}

Received: December 7, 2016

Accepted: January 15, 2017

Online Published: February 5, 2017

DOI: $10.5430 /$ jnep.v7n6p95

URL: http://dx.doi.org/10.5430/jnep.v7n6p95

\begin{abstract}
The current shortage of nurse researchers in geriatrics adversely affects the capacity of nurses to conduct research to advance the evidence-based care of older adults. In an effort to generate interest in geriatrics and geriatric nursing research, the Duke University School of Nursing designed a summer internship for four students enrolled in the accelerated baccalaureate nursing (ABSN) program. This paper describes the experience of these ABSN students and the staff and faculty who worked with them. The program design, staff and faculty experiences, benefits and challenges, as well as recommendations for future programs are discussed. The purpose of this article is to highlight the benefits and challenges of offering research experiences to nursing students in an ABSN program to stimulate interest in geriatrics and geriatric nursing research.
\end{abstract}

Key Words: Accelerated baccalaureate nursing (ABSN), Geriatric nursing, Nursing research, Nursing education, Research training, Long term care

\section{INTRODUCTION}

Despite increased attention to the importance of both geriatric nursing and nursing research for pre-licensure nursing education, ${ }^{[1]}$ implementation of robust geriatrics and geriatrics nursing research in undergraduate curricula remains inadequate. ${ }^{[2]}$ Generating interest in geriatric nursing research is of particular concern as our population continues to age and a global shortage of nurses is predicted ${ }^{[3,4]} \mathrm{Un}-$ fortunately, only $54 \%$ of health professional students show positive attitudes toward the elderly, and only $22 \%$ of nurs- ing students have considered specializing in care for the elderly. ${ }^{[5]}$ Though examples are limited in number, several researchers have tried to generate student interest in geriatrics by providing research opportunities with older adults.

In 1994, $\mathrm{Matzo}^{[6]}$ used two clinical days to have students gather data in a nursing home as part of a larger project. Sidell, ${ }^{[7]}$ working with social work students, assigned them to quantitative research projects in a nursing home setting. Lekan, Corazzini, Gilliss, and Bailey ${ }^{[8]}$ created a learning activity that required students to use evidence for improving

\footnotetext{
*Correspondence: Kirsten N. Corazzini; Email: kirsten.corazzini@ duke.edu; Address: School of Nursing, Duke University, 307 Trent Drive, Durham, North Carolina 27710, United States.
}

Published by Sciedu Press 
care for persons with heart failure and practice the principles of delegation and supervision with nursing staff in nursing homes. In each of these experiences, the students selfreported gains in knowledge of care of older adults, as well as increased interest in research and the value of evidencebased practice. ${ }^{[6-8]}$ Further, a recent study by Kydd, et al. ${ }^{[4]}$ examined nursing student attitudes towards caring for older people and they found that "educators play an important part in shaping attitudes toward older people and helping students see career opportunities in the specialty". ${ }^{[4]}$ Thus, it appears that geriatric nursing researchers might play a key role in helping nursing schools stimulate student interest in both research and care of older adults.

To increase relevance and salience of nursing research in general to entry to practice BSN students, several nurse educators have proposed a more application-based approach to incorporating research into the curriculum of nursing students. Brancato ${ }^{[9]}$ changed the capstone curriculum in a $\mathrm{RN}$ to BSN program to have students work one-on-one with hospital research staff. Similarly, Kennel ${ }^{[10]}$ paired BSN students with hospital research RNs to complete a research project. Wheeler ${ }^{[11]}$ incorporated students in hands-on research opportunities with faculty that provided students with exposure to nursing research. Self-evaluation reports were positive such as "improved ability to read and critique scientific literature and a better understanding of the research process". [11]

Despite the emerging examples of the beneficial effects of such learning experiences on student outcomes, relatively little information exists regarding the perceived challenges or benefits from the perspective of faculty and staff who support such programs. This paper addresses this gap by describing the perspectives of the project coordinator, supervising faculty, and students in a summer, geriatric nursing research internship for students enrolled in the accelerated baccalaureate nursing (ABSN) program in the Duke University School of Nursing. The purpose of describing these perspectives is to inform future, comparable learning experiences. The program was funded by a National Institute of Nursing Research supplemental grant whose parent grant tested an intervention to improve the quality of falls prevention and management care provided to nursing home residents (Anderson/ColonEmeric, R56NR003178 - 09SI; Anderson/Colon-Emeric, R56NR003178-09). The parent research study had dual principal investigators, one a nurse and one a physician, and additional nursing faculty co-investigators. The aim of the supplemental grant was to engage ABSN students in diverse research study activities, including intervention delivery, data collection and analysis, and to foster ABSN student interest in pursuing graduate education in nursing research. Because the Duke University School of Nursing is part of a research 1 doctoral university, ${ }^{[12]}$ undergraduate nursing students have the opportunity to select Duke University for the opportunities to engage in hands-on research activities, which are above and beyond the formal research course. Therefore, the creation of this program met both stated student interest, as well as leveraged extant organizational infrastructure. Both the parent and supplemental grants were approved and overseen by the Duke University Institutional Review Board.

\section{Program design}

The overall program design included the selection of four students from a competitive application process by the nurse principal investigator and two nursing faculty coinvestigators. Students joined the research team under the immediate supervision of the overall research study project director. The nurse principal investigator and nursing faculty co-investigators provided weekly supervision and feedback on campus, and the physician co-principal investigator and project director provided on-site supervision in the nursing homes. Students participated in data collection, data entry and analysis, and assisted in delivering a component of the intervention to nursing home staff.

\section{Student selection}

Two nursing faculty co-investigators distributed a call for applications to all ABSN students in their third semester of the four-semester program and who, at program entry, had declared specific interest in pursuing graduate nursing education and who were enrolled in the research-focused curricular track $(\mathrm{N}=34)$. Student applicants submitted a brief (less than 300 words) essay describing their interest in participating in the research study. Essays were matched with student advisor recommendations to ensure all applicants were in strong academic standing and could balance the additional responsibilities with current coursework. Four students were selected from the pool of applicants.

\section{STUdENT ORIENTATION AND PROGRAM IMPLEMENTATION}

Students were asked to commit ten hours per week to engage in classroom and clinical research activities in the nursing home setting. Two of the participating nursing homes served as sites for the student learning experience. To begin, students completed training in human subjects research, including the Collaborative Institutional Training Initiative (CITI) modules. Following completion of this training, the students were prepared for and participated in two key aspects of the study, including participation in delivering the intervention, and participation in data collection and analysis. 


\subsection{Participation in the intervention}

Before they began research activities in the field, the students met with the project director, research interventionists (including a PhD nursing student), and the nurse and physician co-principal investigators for an overall orientation to the study. Students assisted in delivering the component of the intervention related to prevention of falls among nursing home residents. The project director coordinated students time and observed them in the field during the students' delivery of intervention sessions that consisted of a brief presentation on the prevention of falls to certified nursing assistants, licensed practical nurses, and registered nurses. After the presentation, students facilitated a question and answer session to ensure understanding by the nursing home staff. Also present during the site visits was the physician co-investigator, a geriatrician, who provided student training and supervision on how to implement staff training protocols on fall prevention. Bi-weekly meetings with the students allowed the physician co-investigator to demonstrate the intervention session's flow through role-playing and the students performed return demonstrations one week later to show mastery of both content and teaching methods.

\subsection{Participation in data collection and analysis}

To learn the specific logistics of data collection, the students shadowed the research interventionists on-site in selected nursing homes during data collection where they distributed and collected survey packets. This activity facilitated the student introductions to the nursing home staff, the nursing home layout, and allowed them to become comfortable in their assigned nursing home. The project director was designated to train the ABSN students on survey data collection, tracking, and data entry. Lastly, students also met weekly with the nurse co-principal investigator to address issues related to data collection, to receive progress updates, and to solve problems, as well as to participate in descriptive analyses of the data.

\section{The CHallenges and Benefits}

At the completion of the program, the project director, physician co-principal investigator, and students debriefed regarding the challenges and benefits of student participation in the project. Their experiences are described below.

\subsection{Project director}

Scheduling was the main barrier to incorporating ABSN students into the research project because it was challenging to work around their coursework and clinical commitments. It was also time consuming to train and work with four additional study team members. However, the project director found the students well prepared for presenting the interven- tion sessions. Also, the students demonstrated a high level of commitment to the project and were professional in their representation of the Duke University School of Nursing. The students worked well as a team and were willing to pitch in for each other if another had too many other commitments. Overall, the project coordinator felt that while it took more coordination time to include the students, the value of the contributions of the students far outweighed the extra time spent working with them. In the end, the project director advocated for extending the grant to keep the students on for additional data collection duties and analysis for an extra semester.

\subsection{Supervising faculty}

The physician co-principal investigator identified several challenges in including ABSN students in the research experience. Because of their limited clinical and/or geriatric experience, they required more training and supervision than a clinically experienced research nurse would in delivering the protocols. In addition, there was a concern that their lack of clinical experience would result in nursing home staff being less willing to accept them as presenters of the intervention sessions. To preempt this, we ensured that a medicine or a nursing faculty study team member would be present with them at the sites for all sessions. Thus, substantially more faculty time was required to implement the protocols than normally would have been necessary. Nevertheless, there were important benefits to having the students implement the intervention sessions. Providing the opportunity to deliver an intervention was an important part of the student's research experience and merited the additional faculty time required. The student's energy and enthusiasm were infectious and the nursing home staff readily accepted their teaching. The students also filled a research personnel need during staff transitions. Most importantly, the geriatrician appreciated the opportunity to cultivate research interest among talented nursing students, as this was an important personal and institutional goal, especially in the field of geriatrics where trained providers are urgently needed. Thus, she found the experience of working with ABSN students professionally and personally satisfying.

\subsection{Students}

The four students uniformly considered the research internship experience to be beneficial. Benefits they recounted included the opportunity to diversify their educational experience, apply what they learned in a classroom to real life, experience the feeling of being a knowledgeable specialist, and to participate in significant one-on-one interactions with faculty-researchers. The research project provided a different way in which to learn about geriatrics. The students 
welcomed the change from classroom learning and found their work, in the context of the project, more meaningful. In addition, students learned about the research process and how research can positively impact practice. They were exposed to the many aspects of designing, planning, executing, and evaluating a large-scale, NIH-funded research project. Prior to this experience, most of them had very little understanding of the research process or the vast efforts that go into it. The students now appreciate the amount of time, energy and resources that must be dedicated to such a venture. Such are many of the advantages of experiential learning. ${ }^{[13]}$

The students gained confidence in and reinforced their knowledge of geriatric care when they served as a falls intervention specialist at the nursing homes by educating others during the intervention sessions and by serving as a resource for other healthcare professionals. They learned to work with nursing staff at all levels from nurse aids to nursing administration. The experience allowed them to develop technical and interpersonal skills that will certainly be of use later in their academic and professional careers. And, the experience provided a reprieve from the frustration sometimes felt by second-degree students transitioning back to learners after they were competent in another field before nursing school. ${ }^{[14]}$

Finally, one-on-one instruction with the nurse principal investigator, nursing faculty co-investigators, physician coprincipal investigator, and $\mathrm{PhD}$ nursing student provided an invaluable mentorship opportunity. The small group meetings provided a nonthreatening environment in which to think critically, and exchange ideas with each other and with faculty. The students also found that it was a great opportunity to glean valuable information and expert advice on a variety of topics from research study procedures and statistical analysis to academic success and career path options. Research shows that mentorship can be a powerful tool for supporting students in academia and, not surprisingly, the students felt that they greatly benefited from the personal interaction and relationships built with the faculty advisors and principle investigators involved in the study. ${ }^{[15]}$

\section{RECOMMENDATIONS}

Flexibility from research team staff, nursing home staff, and students, was an important factor that contributed to the success of this project. Due to the nature of the project and the number of people involved (i.e. nursing home staff, interventionists, faculty), schedules changed constantly. Fortunately, the small group size allowed for easier communication and students worked well together to fill in for each other if one had a conflict. They maintained a high level of professionalism and commitment to the project and were always willing to help each other. It is also recommended that participating students, while they may have separate projects, are brought together periodically for group instruction. This allows for more students to participate while minimizing the time spent instructing them. In this research experience, students were trained together, reducing staff and faculty commitment. Yet, students still worked independently to collect and analyze data, and to deliver intervention components. Carson ${ }^{[16]}$ described a similar technique in her paper where she designed a program to increase laboratory research opportunities for undergraduate students. By giving students independent projects but training them in parallel, Carson reduced mentor time burden without affecting the quality of the research experience. Lastly, it was important that faculty and staff advisors constantly acknowledged and encouraged students to make course work their priority so that students never felt that either experience was compromised. A careful initial selection process ensured that all participating students began with strong organizational and time management skills, which was essential to the success of the program.

Since completion of their ABSN degree, two of the students initially took nursing jobs on geriatric floors in a hospital. Eventually, these same two nurses moved into clinical research coordinator positions. Three of the students continued their education into advanced practice. And two of the four maintain that they eventually hope to pursue a $\mathrm{PhD}$ in nursing. One student stated that the research program allowed her to "better understand the importance of nursing research as a masters-level student". These latter points are particularly important in the context of the interdisciplinary team implementing the project. Whether mentored by the physician co-principal investigator or the nurse co-principal investigator, these nursing students could see how interdisciplinary research teams are contributing to nursing research, and the relevance of this research. Another stated that the experience "helped her to better support and care for her elderly patients and their families". All four students agree that participating in the program was an important part of their undergraduate experience.

\section{Conclusion}

To date, we have not identified any descriptions of programs that have worked with ABSN students in this type of learning experience. ABSN students represent a unique group of individuals who typically hold degrees in non-nursing fields that have chosen to make a career change into nursing. They bring experiences to nursing from past degrees and careers, are highly motivated, and are excellent learners. As one of the fastest growing segments of nursing programs, they are perhaps an untapped source of potential nurse scientists. ${ }^{[17]}$

ISSN 1925-4040 E-ISSN 1925-4059 
ABSN programs might be a way to fast track these students into research to help fill the need for PhD prepared nurses. In addition, small grant projects such as this one offered a unique learning experience to help stimulate student interest in geriatrics, an area that is often underdeveloped in nursing programs.

\section{ACKNOWLEDGEMENTS}

We would like to thank the following students for their contributions to this paper: Megan Bowers, Maggie Mucha, and Katy Zahn.

\section{CONFLicts OF INTEREST Disclosure}

The authors declare that there is no conflict of interest.

\section{REFERENCES}

[1] American Association of Colleges of Nursing. Nurse faculty tool kit for the implementation of the baccalaureate essentials [Internet]. Washington (DC). 2009 [cited 2016 Nov 11]. Available from: http://www . aacn.nche.edu/faculty/faculty-devel opment/faculty-toolkits/BacEssToolkit.pdf

[2] Institute of Medicine (US). The future of nursing: leading change, advancing health [Internet]. Washington (DC). 2010 [cited 2015 Mar 22]. Available from: http://www.iom.edu/Activities/Workf orce/Nursing. aspx

[3] Mass ML, Conn V, Buckwalter KC, et al. Increasing nursing faculty research: the Iowa gerontological nursing research and regional consortium strategies. Journal of Nursing Scholarship. 2009; 41(4): 411-419. https://doi.org/10.1111/j.1547-5069.20 $09.01309 \cdot \mathrm{x}$

[4] Kydd A, Touhy T, Newman D, et al. Attitudes towards caring for older people in Scotland, Sweden, and the United States. Nursing Older People. 2014; 26(2): 33-40. https ://doi.org/10.7748/ nop2014.02.26.2.33.e547

[5] Zambrini B, Moraru M, Hanna M, et al. Attitudes toward the elderly among students of health care related studies at the University of Salamanca, Spain. Journal of Contin Educ Health Prof. 2008; 28(2): 86-90. PMid:18521885 https://doi .org/10.1002/chp. 162

[6] Matzo M. Baccalaureate nursing students as research clinicians in long-term care. Geriatric Nursing. 1994; 15(5): 250-251. https: //doi.org/10.1002/chp.162

[7] Sidell NL. Teaching qualitative research to BSW students through exposure to aging. Journal of Gerontological Social Work. 2007; 50: 91-104. https://doi.org/10.1300/J083v50n01_07

[8] Lekan DA, Corazzini KN, Gilliss CL, et al. Clinical leadership development in accelerated baccalaureate nursing students: an education innovation. Journal of Professional Nursing. 2011; 27(4): 202-214. https://doi.org/10.1016/j.profnurs .2011.03.002
[9] Brancato VC. An innovative clinical practicum to teach evidencebased practice. Nurse Educator. 2006; 31: 195-199. https ://doi . org/10.1097/00006223-200609000-00004

[10] Kennel S, Burns S, Horn H. Stimulating student interest in nursing research: A program pairing students with practicing clinician researchers. Journal of Nursing Education. 2009; 48: 209-212. https://doi.org/10.3928/01484834-20090401-06

[11] Wheeler EC, Hardie T, Schell K, et al. Symbiosis-Undergraduate research mentoring and faculty scholarship in nursing. Nursing Outlook. 2008; 56: 9-15. https://doi.org/10.1016/j.outlook. 2007.09.001

[12] Center for Postsecondary Research, Indiana University School of Education. Carnegie Classification of Institutions of Higher Education [Internet]. 2015 [cited 2017 Jan 20]. Available from: http: //carnegieclassifications.iu.edu/downloads.php

[13] Phillips RM, Bonsteel SH. The faculty and information specialist partnership stimulating student interest and experiential learning Nurse Educator. 2010; 35(3): 136-138. https://doi.org/10.1 097/NNE. 0b013e3181d95090

[14] Utley-Smith Q, Phillips B, Turner K. Avoiding socialization pitfalls in accelerated second-degree nursing education: The returning-toschool syndrome model. Journal of Nursing Education. 2007; 46(9): 423-426. PMid: 17912995

[15] Leake DW, Burgstahler S, Izzo MV. Promoting transition success for culturally and linguistically diverse students with disabilities: the value of mentoring. Creative Education. 2011; 2(2): 121-129. https://doi.org/10.4236/ce.2011.22017

[16] Carson S. A new paradigm for mentored undergraduate research in molecular microbiology. CBE-Life Sciences Education. 2007; 6: 343-349.

[17] American Association of Colleges of Nursing. Accelerated nursing programs: the fast track to careers in nursing [Internet]. 2002 [revised $2013 \mathrm{Jan}$; cited 2015 Mar 22]. Available from: http://www.aacn.nche.edu/publications/issue-b ulletin-accelerated-programs 